\title{
Study on the Construction of Agricultural Products E-commerce Logistics System in Jiangxi Province
}

\author{
Guohui Li ${ }^{1, \text { a }}$, Zehui Chen ${ }^{1, b}$ \\ ${ }^{1}$ Nanchang Institute of Science \& Technology, Nanchang, Jiangxi, 330000 \\ ${ }^{\mathrm{a}}$ email, ${ }^{\mathrm{b}}$ email
}

Keywords: Agricultural Products, E-commerce Logistics System, Jiangxi Province

\begin{abstract}
E-commerce and the rapid development of communication technology for the development of agricultural products market provides a good platform, all over the country have set up various types of agricultural products business more than 3,000 enterprises, agricultural products, rapid development and fierce competition in e-commerce. The traditional logistics and distribution is difficult to adapt to the development and demand of logistics and distribution of agricultural products under the e-commerce, the new distribution demand is emerging, and the new distribution system needs to be solved urgently to solve the bottleneck problem of logistics and distribution of agricultural products. China's e-commerce under the logistics and distribution of agricultural products has been rapid development, there have been a variety of business models and logistics and distribution system, but the logistics cycle is long, loss, high cost of the problem is still not resolved. At present, Jiangxi's agricultural products can not be centralized and coordinated operation, resulting in increased logistics and distribution costs, and difficult to meet customer demand for agricultural products logistics and distribution "multi-species, small batch, multi-batch, short cycle" requirements.
\end{abstract}

\section{Introduction}

E-commerce refers to the use of electronic information networks and other electronic means of business activities, business activities are electronic, information and network. It appears to break through the limitations of traditional business in time and space, so that modern business activities are safe, reliable, fast, clear and convenient features, through the INTERNET we can carry out e-commerce activities anytime, anywhere; it also changes the traditional transaction Model, a booster of modern economic development, creating a business enterprise one after another myth, from eBay to Taobao, from Amazon to Alibaba. However, as a big agricultural country, e-commerce can bring miracles in Jiangxi agricultural products has been slow to achieve, the author through the Alexa website ranking query found that China's e-commerce site Taobao ranked No. 21, Alibaba No. 23, And as China's largest agricultural e-commerce platform for the world's agricultural network ranked 131,848, although the contrast of the three e-commerce sites face the types of users and trading products are different characteristics, but the rankings so disparity, to a certain extent But also reflects the development of e-commerce products and other commodity e-commerce development there is a big difference. It is true that agricultural products have their particularities, such as life, dependency, environmental dependence, process multiplexing, regional differences, quality instability, uncertainty, etc., which put forward the production and circulation of Jiangxi agricultural products more High demand. In the traditional agricultural product logistics system, the flow of information, the business flow, the logistics and the capital flow are separated from each other in time and space, and the structural contradiction formed by the agricultural products in the production, Based on the analysis of the status quo of Jiangxi agricultural product logistics system, this paper constructs the modern agricultural product logistics system with information flow, business flow and logistics integration through the advantage of electronic commerce. 


\section{Analysis on Present Situation of Agricultural Products Logistics System in Jiangxi}

Jiangxi agricultural products logistics to the normal temperature logistics or natural logistics, agricultural products in the circulation process loss is great, the statistics show that China's fruits and vegetables and other agricultural and sideline products in the logistics link on the loss rate of $25 \%$ to $30 \%$, while the developed countries Of the loss rate is controlled at $5 \%$, the United States only $1 \%$ to $2 \%$. Leading to the high cost of Jiangxi agricultural products are mainly due to:

Circulation of the main body too much, too long production and marketing chain. The main body of agricultural products logistics include: agricultural production and processing and sales of enterprises and individuals to provide agricultural products logistics services organization. China has 900 million farmers, 2.4 million farmers brokers, 95 million operating large, 170,000 rural cooperation and intermediary organizations, 50,000 agricultural industrialization leading enterprises, such a huge circulation of the main subject will inevitably lead to higher transaction costs. In addition, most of China's agricultural products will generally go through several links: producers origin market - marketing wholesalers - sales market retailers - consumers, too long production and marketing chain will lead to higher circulation cost.

The interactive transport network has not yet been formed and the transportation costs are high. China's vast territory, complex terrain, regional differences between the larger, which Jiangxi agricultural transport put forward higher requirements, but China's three-dimensional interactive transport network has not yet formed, agricultural products in different regions will lead to higher circulation cost.

Storage processing and preservation of backward technology, large flow loss. Jiangxi agricultural products, storage and processing technology is lagging behind the backward, the vast majority of agricultural products from the origin of the original product in the form of sales, making agricultural products in the circulation of serious wear and tear, an indirect increase in the cost of circulation.

\section{Overview of E-commerce Logistics Distribution System for Agricultural Products}

The level of logistics and distribution of agricultural products is high. Agricultural products logistics and distribution of time, preservation has strict requirements. With the continuous emergence of food safety issues in society, the distribution of agricultural products need to be able to monitor the traceability of the function, on the basis of this must also be on time and quantity of agricultural products to the hands of customers. Agricultural logistics and distribution of facilities and equipment are requirements. Agricultural logistics distribution and general logistics and distribution is different. Due to the particularity of agricultural products, in the distribution of agricultural products in the distribution technology, distribution equipment requirements are not the same. For example, in the storage link need to use the freezing, insulation and other facilities for storage. The process of fresh agricultural products needs to use the entire cold chain distribution equipment to operate. As China's cold chain logistics development is slow, distribution companies are still unable to meet the cold chain distribution requirements, can not have the entire cold chain equipment. Agricultural products logistics and distribution is by the impact of the season and cycle. Due to the seasonal characteristics of agricultural products, agricultural products logistics and distribution business also showed corresponding seasonal changes. In addition, agricultural products affected by climate and other factors, the quality of agricultural products and production there is a great deal of instability. In this case, the logistics and distribution of agricultural products need to allocate resources according to the adjustment of agricultural resources, that is, with the seasonal and periodic deployment of agricultural products. Agricultural products in rural areas in the production, consumption in the city, formed from the rural to urban one-way circulation process. Electric business enterprises to carry out the distribution of agricultural products, the level of service delivery has strict requirements to meet customer needs in the case of reducing logistics and distribution costs is the key to corporate profits. Although the business through e-commerce will reduce product circulation, reduce transaction costs, but the distribution of agricultural products on 
the fresh, the requirements of the distribution process makes the more complex. Therefore, enterprises engaged in agricultural product logistics and distribution is more sensitive to cost fluctuations.

Construction of e-commerce based on agricultural logistics system is based on the premise of the Internet to information technology as the basis, to e-commerce as a means to third-party logistics for the protection of the supply chain nodes to establish a strategic partnership to achieve from the producers , Distributors, retailers to the final consumer business flow, logistics, information flow and capital flow in the entire supply chain unimpeded, the original separation of production, procurement, transportation, warehousing, agents, distribution and other logistics links closely linked , To achieve the entire agricultural supply chain seamless docking, and ultimately achieve a win-win or even win the purpose of agricultural products circulation, information sharing to provide solutions to build a farmer, business, government, consumers build agricultural products logistics e-commerce system.

We can see the Internet is the link between the nodes of agricultural products, through the Internet agricultural producers can understand the market demand information, and targeted production, so as to ensure that the balance of supply and demand of agricultural products, narrowing the market price of agricultural products, reduce the market Risk; logistics brokers can be based on the supply of agricultural information and demand information, a reasonable organization of warehousing and transportation, to reduce the origin of agricultural products in the supply of oversupply, the supply of land in short supply phenomenon, reduce the information brought about by the operational risks; Through the network to understand the supply of agricultural information and market price information, reduce the loss caused by information asymmetry. Therefore, the construction of the Internet, especially the rural Internet construction is the basic premise of the electronic logistics of agricultural products, although this premise has not yet been achieved in the current stage, only $0.8 \%$ of farmers in China can access the Internet, compared to $51 \%$ of the United States, Brazil 14\% There is a big gap, but has been the relevant government departments attention, such as the Ministry of Information Industry in 2006, No. 229 "on the promotion of socialist new rural construction work" mentioned "vigorously promote the rural Internet construction and to ensure that the basic implementation of the 11th Five-Year Rural to the Internet to the Internet planning objectives, "I believe that this premise will be achieved in recent years.

The most efficient mode of operation for the community to provide the best quality service, which not only requires a higher level of management, but also have advanced technology for the service, which requires modern logistics system to absorb and use many representatives of today's scientific and technological development level of modernization Technology, but also its own continuous innovation and development of many unique logistics technology. (GIS), global satellite positioning system (GPS), bar code technology (Bar Code), radio frequency technology (RF) as the basis; from the environmental system technical level, the need for electronic Data exchange (EDI) support; in the operation management technology level, the need for timely technology (JIT), classification management technology $(\mathrm{ABC})$ to do support; at the time of sales management technology, the need for sales point information system (POS), effective Customer information feedback (ECR), automatic continuous replenishment technology (CEP), and fast response (QR). However, the application of these technologies in the logistics system of Jiangxi agricultural products is still in the initial stage. To realize the electronic logistics of Jiangxi agricultural products, it is necessary to speed up the application of information technology.

With the development of agricultural products logistics, high cost, low efficiency of the opponent trading model has been difficult to adapt to the requirements of agricultural circulation, the market calls for more advanced, immediate and efficient trading model. E-commerce is a good means of reference, its wide use, is conducive to reducing the flow of agricultural products, shorten the supply chain, to build a "agricultural producers - rural sales cooperation organization - e-commerce wholesale market - online retailers-the ultimate consumer "new agricultural e-commerce circulation chain, shorten the circulation time, reduce the frequency of transactions, reduce the cost of 
circulation, change the market bar, information asymmetry, lack of full competition in the market environment, improve market transparency and fairness, Responsive, sound and effective fair price formation mechanism and large scale, smooth information, high transparency, full competition in the national agricultural products unified market, Jiangxi agricultural products circulation and the development of agricultural economy will inevitably play a huge role in promoting. Therefore, to achieve the electronic logistics of agricultural products, e-commerce is an essential means of indispensable.

\section{Conclusion}

Jiangxi modern agricultural product logistics system development has just started, there are high cost of circulation, circulation of the main body, long distribution channels, trading means backward, organized, low degree of information technology status quo. To solve these problems, we must use advanced network technology to rely on e-commerce, tangible market and intangible market organic combination, to build a new e-commerce based on agricultural logistics system, promote the development of Jiangxi agricultural information, the formation of agricultural products New strategic new initiatives.

\section{Acknowledgements}

2016 Jiangxi Province Project in College of Humanities and Social Sciences Proj. No. JC162045

\section{References}

[1] Pan Dongjing. Study on Optimization of Distribution Route of Agricultural Products Cold Chain Logistics Vehicles with Fuzzy Demand [J]. Journal of Anhui Agricultural Sciences, 2015 (05)

[2] Tan Bo.Study on optimization of distribution route of agricultural products [J]. Logistics Technology, 2014 (05)

[3] Zhang Huizhen, Li Shumei, Zhang Zhongxin. Research on the Construction of Agricultural Products Logistics Distribution System Based on E-commerce Information Platform [J]. Today's China Forum, 2013 (19)

[4] Hu Baofang. Improved genetic algorithm for multi-distribution center oriented to customer priority in cloud distribution [J]. Logistics Technology, 2013 (15)

[5] Zou Xiaomei, Li Qianlan, Liu Feiqi. Study on the Construction of Agricultural Products Circulation Model in Hunan Province [J]. China Business, 2012 (22) 